\title{
STRUCTURAL DIFFERENCES AND ASYMMETRIC SHOCKS BETWEEN THE CZECH ECONOMY AND THE EURO AREA 12
}

\author{
Martin Slanicay \\ Masaryk University, Faculty of Economics and Administration, Department of \\ Economics, Lipová 41a, Brno 602 00, slanicay@ mail.muni.cz
}

\begin{abstract}
The goal of this paper is to determine whether there exist asymmetric shocks and structural differences between the Czech economy and the Euro Area 12. A New Keynesian DSGE model of a small open economy is used for this purpose. Asymmetric shocks and structural differences are examined in two ways. At first, I examine asymmetry of shocks and sources of structural differences, using model comparison based on the Bayes factor. I do not find substantial evidence in favor of heterogeneity in household preferences. I find slight differences in price and wage formation and substantial difference in interest rate smoothing. However, the main differences are in timing, persistence and volatility of structural shocks. I also investigate impact of structural differences and differences in persistence and volatility of structural shocks on the behavior of both economies, using analysis of impulse-response functions. I find no substantial differences in responses of the main variables to preference shocks. On the other hand, I find much larger volatility and persistence of domestic technology shocks. This contributes to the fact that responses of domestic variables to technology shocks are much larger, and display more gradual and hump-shaped pattern than responses of foreign variables. I also find that responses of foreign variables to labour supply shocks are much more gradual and sluggish than responses of domestic variables. As regards monetary shocks, I find that there is almost no response of foreign inflation to foreign monetary shock while response of domestic inflation to domestic monetary shock displays substantial decline followed by gradual recovery. Responses of foreign variables to cost-push shocks are larger and more volatile than responses of domestic variables.
\end{abstract}

Key words: New Keynesian, DSGE model, Bayes factor, Bayesian estimation, structural differences, asymmetric shocks, model comparison.

JEL Classification: C51, E32, E52

DOI: $10.2478 / \mathrm{v} 10135-011-0012-0$ 


\section{STRUCTURAL DIFFERENCES AND \\ ASYMMETRIC SHOCKS BETWEEN THE CZECH ECONOMY AND THE EURO AREA 12'}

Martin Slanicay ${ }^{2}$

\section{Introduction}

Asymmetric shocks and structural differences are regarded as the main causes of a potential suboptimality of common monetary policy. Asymmetry of shocks is defined as differences in timing, magnitude or persistence of structural macroeconomic shocks. Structural differences are then defined as differences in propagation mechanisms of structural shocks. In case of asymmetric shocks and (or) structural differences in a monetary union, applied monetary policy facing structural shocks must be suboptimal for some countries. Therefore, analysis of asymmetric shocks and structural differences plays an important role in evaluating benefits and costs of common currency.

The goal of this paper is to investigate the asymmetric shocks and structural differences between the Czech economy and Euro Area. A New Keynesian DSGE model of a small open economy developed by Justiniano and Preston (2010) is used for this purpose. The model is built on the framework of Galí and Monacelli (2005), and Monacelli (2003), who developed an elegant model of small open economy with price rigidity modelled in Calvo style, see Calvo (1983). The latter paper, building directly on the former, extends the former by introducing an incomplete pass-through. Another extension is brought by Justiniano and Preston (2010a) who extended this framework by allowing for habit formation, price indexation and incomplete asset market. The model of Justiniano and Preston (2010b) used in this study extends the previous one by introducing wage rigidity modelled in Calvo style, following a benchmark for staggered wage contracts from Ergeg, Henderson and Levin (2000). I have altered this model in a few aspects. Following Adolfson et al. (2008), I have modified the uncovered interest rate parity condition (UIP condition) by giving a positive weight to the lagged real exchange rate. Following Kolasa (2009), I also allow for correlations between corresponding shocks in both economies.

Asymmetric shocks and structural differences are examined in two ways. Firstly, I examine asymmetry of shocks and sources of structural differences, using model comparison based on a Bayes factor. In the context of DSGE models, we can view structural differences (asymmetric shocks) as significant differences in values of some structural parameters (parameters related to shocks). Following Kolasa (2009), I use Bayesian approach for testing significance of these differences. A difference in parameter value is regarded as significant if the data fit of models which allow for different values of this parameter in both economies are better than the data fit of those

\footnotetext{
1 This work was supported by funding of specific research at ESF MU, project MUNI/A/0943/2009 and by MŠMT project Research centers 1M0524.

2 Masaryk University, Faculty of Economics and Administration, Department of Economics, Lipová 41a, Brno 602 00, slanicay@ mail.muni.cz
} 
models with common value of this parameter in both economies. The data fit measure is a Bayes factor (BF) calculated from marginal likelihood, which are acquired from estimation. Secondly, I examine how structural differences and differences in persistence and volatility of structural shocks influence behavior of both economies. I analyze differences in responses of the main macroeconomic variables in both economies to corresponding shocks in these economies, using impulse-response functions.

\section{Related Papers}

Much economic research deals with these issues because of their important role in evaluating benefits and costs of common currency. Pauer (1996) provides a nontechnical overview of a role of asymmetric shocks in a debate about benefits and costs of common currency.

Several authors try to determine to what extent are the shocks within EU asymmetric. Bayoumi and Eichengreen (1992) find that shocks are significantly more idiosyncratic across EU countries than across US regions, which may indicate that the EU will find it more difficult to operate a monetary union. On the other hand, Verhoef (2003) shows that symmetries of demand and supply shocks increase over time within EMU.

Some studies deal with an adjustment process to asymmetric shocks. Alexius and Post (2008) examine how floating exchange rates respond to asymmetric shocks, and find out that exchange rates display some stabilizing properties but can mainly be characterized as disconnected from the rest of the economy. Amisano, Giammarioli and Stracca (2009) examine the adjustment process to asymmetric shocks in Italy and argue that joining EMU does not alter the adjustment process to idiosyncratic demand and cost push shocks, and that the EMU system is not hit by idiosyncratic monetary shocks anymore. Driver and Wren-Lewis (1999) try to quantify the costs imposed by asymmetric shocks under EMU compared to free floating. Their results suggest that these costs are significantly higher under EMU than under free floating.

Several papers discuss the presence and relative importance of asymmetric shocks and structural differences. Jondeau and Sahuc $(2007,2008)$ test the structural heterogeneity within Euro Area and come to the conclusion that asymmetric shocks are the main sources of a different behavior of countries in Euro Area, while structural differences play almost no role. Kolasa (2009) investigates structural heterogeneity between Poland and Euro Area and finds out that volatility and synchronization of shocks hitting both economies are the main sources of structural heterogeneity. Pytlarczyk (2005) estimates a two country DSGE model of Germany and the rest of Euro Area. He finds out that the unrestricted model with the stochastic heterogeneity and a different composition of consumption and investment baskets across the regions fits the data better than the restricted model with the stochastic homogeneity and identical composition of these baskets.

Many authors examine structural differences alone. Benigno and López-Salido (2006) find differences in inflation dynamics between Germany on the one side, and France, Italy, the Netherlands and Spain on the other. They discover that inflation dynamics in Germany is characterized by a forward-looking nature of price setting and average duration of prices of about 5 quarters, while the other group of countries is characterized 
more by a backward-looking nature of price setting and average duration of prices of about 8 quarters. Fabiani and Morgan (2003) examine differences in the relationship between wage growth, inflation and tightness of the labor market across Germany, France, Italy, the Netherlands and Spain. They provide empirical evidence that there exist large differences even across these "core" countries. Angeloni and Ehrmann (2004) try to explain why differences in national inflation rates and growth rates arise within the Euro Area. They find out that the main explanation can be ascribed to differences in inflation persistence. Campa and González Minguez (2006) investigate exchange rate pass-through in Euro Area countries. They find substantial differences across Euro Area countries in the way how a common exchange rate movement gets transmitted into prices. Most of these differences are caused by a distinct degree of openness of each country to non-euro area imports rather than by heterogeneity in the structure of imports. Demertzis and Hugues Hallett (1998) investigate differences in unemployment rates in Europe. They show that disparities in unemployment rates are brought about mainly by differences in labor market fundamentals causing natural rate of unemployment to differ. Asymmetric shocks and policy differences, both causing differences in unemployment gap, play a limited role in explaining unemployment disparities. Cecchetti (1999) provides the evidence that differences in a financial structure influence the transmission mechanism of the monetary policy. He shows that countries with poorer direct capital access, less concentrated and less healthy banking systems display a greater sensitivity of inflation and output to policy changes.

\section{Model}

Derivation of the model from microfoundations can be found in Justiniano and Preston (2006, 2010b). The model is in the log-linear form, so all variables are in the form of $\log$-deviations from their respective steady state, formally $x_{t}=\log X_{t}-\log \bar{X}$, where $\bar{X}$ is a steady state value. Variables and parameters with the superscript “*” hold for the foreign economy.

\section{Domestic Block}

Log-linear approximation of Euler equation for intertemporal decisions of domestic households is in the form

$$
c_{t}-h c_{t-1}=E_{t} c_{t+1}-h c_{t}-\frac{1-h}{\sigma}\left(i_{t}-E_{t} \pi_{t+1}+E_{t} \varepsilon_{g, t+1}-\varepsilon_{g, t}\right),
$$

where $c_{t}, i_{t}, \pi_{t}$ is consumption, nominal interest rate and inflation in the period $t, E_{t}$ denotes expectations in the period $t, h$ is a parameter of habit formation in consumption, $\sigma$ is an inverse elasticity of intertemporal substitution in consumption and $\varepsilon_{g, t}$ is a preference shock in the period $t$ in the form of AR1 process. Goods market clearing condition requires

$$
(1-\alpha) c_{t}=y_{t}-\left(\alpha \eta^{*}+\alpha \eta(1-\alpha)\right) s_{t}-\alpha \eta^{*} \psi_{F, t}-\alpha y_{t}^{*}
$$


where $y_{t}, y_{t}^{*}, s_{t}$ denotes domestic and foreign output and terms of trade in the period $t$, $\alpha$ is a parameter of the openness of a domestic economy, $\eta, \eta^{*}$ is an elasticity of substitution between domestic and foreign goods, and $\psi_{F, t}$ is a law of one price gap defined as

$$
\psi_{F, t}=\left(e_{t}+p_{t}^{*}\right)-p_{F, t}
$$

where $e_{t}$ is a nominal exchange rate, $p_{t}^{*}$ is a foreign price index and $p_{F, t}$ is a price index of imported goods. Terms of trade $S_{t}$ are defined standardly as $S_{t}=P_{F, t} / P_{H, t}$, and after log-linearizing and time differencing we get

$$
\Delta s_{t}=\pi_{F, t}-\pi_{H, t}
$$

where $\pi_{F, t}$ is inflation of imported goods and $\pi_{H, t}$ is inflation of domestic goods. Terms of trade $s_{t}$, law of one price gap $\psi_{F, t}$ and the real exchange rate $q_{t}$ are related in an identity

$$
q_{t}=\psi_{F, t}+(1-\alpha) s_{t}
$$

Firms maximize their profits subject to a set of demand constraints and to the Calvo constraint on the frequency of price adjustment. According to the Calvo constraint, only $1-\theta_{p}$ portion of producers reset their prices optimally every period, while a fraction $\theta_{p}$ adjust their prices according to an indexation rule $\log P_{H, t}(i)=\log P_{H, t-1}(i)+\delta_{p} \pi_{H, t-1}$. The result of optimal price settings of firms is a rule for development of domestic inflation

$$
\pi_{H, t}-\delta_{p} \pi_{H, t-1}=\beta E_{t}\left(\pi_{H, t+1}-\delta_{p} \pi_{H, t}\right)+\xi_{p}\left(w_{t}+s_{t}+\psi_{t}\right)+\varepsilon_{c p, t},
$$

where

$$
\begin{aligned}
& \xi_{p}=\frac{\left(1-\theta_{p}\right)\left(1-\beta \theta_{p}\right)}{\theta_{p}\left(1+\omega_{p} \varepsilon_{p}\right)}, \\
& \psi_{t}=\left(1+\omega_{p}\right) \varepsilon_{a, t}-\omega_{p} y_{t},
\end{aligned}
$$

$\theta_{p}$ is a parameter of domestic price stickiness, $\delta_{p}$ is a parameter of domestic price indexation, $\beta$ is a discount factor, $\varepsilon_{p}$ is an elasticity of substitution among domestic goods, $\omega_{p}=-f^{\prime} \bar{Y} /\left(f^{\prime}\right)^{2}>0, f$ is a production function of domestic producers which satisfies usual Inada conditions, $w_{t}$ is a real wage, $\varepsilon_{a, t}$ is a domestic technology 
shock in the form of AR1 process, and $\mathcal{E}_{c p, t}$ is a firm's cost-push shock in the form of IID process, added for estimation purposes.

Importers maximize their profits subject to a set of demand constraints and to the Calvo constraint on the frequency of price adjustment. According to the Calvo constraint, every period only $1-\theta_{F}$ portion of importers reset their prices optimally, while a fraction $\theta_{F}$ adjust their prices according to the indexation rule $\log P_{F, t}(i)=\log P_{F, t-1}(i)+\delta_{F} \pi_{F, t-1}$. The result of optimal price settings of importers is a rule for development of imported inflation

$$
\pi_{F, t}-\delta_{F} \pi_{F, t-1}=\beta E_{t}\left(\pi_{F, t+1}-\delta_{F} \pi_{F, t}\right)+\xi_{F} \psi_{F, t}+\varepsilon_{c f, t},
$$

where

$$
\xi_{F}=\frac{\left(1-\theta_{F}\right)\left(1-\beta \theta_{F}\right)}{\theta_{F}}
$$

$\theta_{F}$ is a parameter of import's price stickiness, $\delta_{F}$ is a parameter of import's price indexation and $\varepsilon_{c f, t}$ is a cost-push shock in the form of AR1 process.

Households maximize their utility function subject to a set of labor demand constraints and to the Calvo constraint on the frequency of wage adjustment. According to the Calvo constraint, only $1-\theta_{w}$ portion of households reset their wages optimally every period, while a fraction $\theta_{w}$ adjust their wages according to the indexation rule $\log W_{t}(k)=\log W_{t-1}(k)+\delta_{w} \pi_{t-1}$. The result of optimal wage settings of households is a rule for development of wage inflation

$$
\pi_{t}^{w}-\delta_{w} \pi_{t-1}=\beta E_{t}\left(\pi_{t+1}^{w}-\delta_{w} \pi_{t}\right)+\xi_{w}\left(v_{t}-w_{t}\right)
$$

where

$$
\begin{gathered}
\xi_{w}=\frac{\left(1-\theta_{w}\right)\left(1-\beta \theta_{w}\right)}{\theta_{w}\left(1+\varphi \varepsilon_{w}\right)}, \\
v_{t}=\varphi\left(y_{t}-\varepsilon_{l, t}\right)+\frac{\sigma}{1-h}\left(y_{t}-h y_{t-1}\right),
\end{gathered}
$$

$\theta_{w}$ is a parameter of wage stickiness, $\delta_{w}$ is a parameter of wage indexation, $\varphi$ is an inverse elasticity of labor supply, $\varepsilon_{l, t}$ is a labor supply shock in the form of AR1 process. Price inflation, wage inflation and the real wage are connected in an identity

$$
w_{t}=\pi_{t}^{w}-\pi_{t}+w_{t-1} .
$$


Terms of trade, inflation of domestic goods and overall domestic inflation are connected in an identity

$$
\pi_{t}=\pi_{H, t}+\alpha \Delta s_{t}
$$

Following Adolfson et al. (2008) I used a modified version of the uncovered interest rate parity condition ${ }^{1}$

$\left(i_{t}-E_{t} \pi_{t+1}\right)-\left(i_{t}^{*}-E_{t} \pi_{t+1}^{*}\right)=\left(1-\phi_{q}\right) E_{t} \Delta q_{t+1}-\phi_{q} \Delta q_{t}-\chi a_{t}+\varepsilon_{s, t}$,

where $\chi$ is an elasticity of foreign interest rate to debt, $\phi_{q}$ is a parameter of modified UIP condition, $\varepsilon_{s, t}$ is a risk premium shock in the form of AR1 process and $a_{t}$ is a real net foreign asset position expressed as a fraction of domestic output steady state which has to satisfy flow budget constraint condition in the form

$$
c_{t}+a_{t}=\frac{a_{t-1}}{\beta}-\alpha\left(s_{t}+\psi_{F, t}\right)+y_{t} .
$$

Domestic block of the model is completed with a monetary policy rule in the form of modified Taylor rule, for the evolution of domestic nominal interest rates

$$
i_{t}=\rho_{i} i_{t-1}+\left(1-\rho_{i}\right)\left[\psi_{\pi} \pi_{t}+\psi_{y} y_{t}\right]+\varepsilon_{M, t},
$$

where $\rho_{i}$ is a parameter of interest rate smoothing, $\psi_{\pi}$ is an elasticity of interest rate to inflation, $\psi_{y}$ is an elasticity of interest rate to output, and $\varepsilon_{M, t}$ is a monetary shock in the form of IID process.

\section{Foreign Block}

Foreign block is a closed economy version of that presented above. All variables and parameters have the same interpretation as in the domestic economy, and are distinguished from those of domestic economy by superscript "*". Intertemporal decisions of foreign households are described by Euler equation

$$
y_{t}^{*}-h^{*} y_{t-1}^{*}=E_{t} y_{t+1}^{*}-h^{*} y_{t}^{*}-\frac{1-h^{*}}{\sigma^{*}}\left(i_{t}^{*}-E_{t} \pi_{t+1}^{*}+E_{t} \varepsilon_{g, t+1}^{*}-\varepsilon_{g, t}^{*}\right) \text {. }
$$

Price setting behavior of foreign firms is described by the price Phillips curve

$$
\pi_{t}^{*}-\delta_{p}^{*} \pi_{t-1}^{*}=\beta E_{t}\left(\pi_{t+1}^{*}-\delta_{p}^{*} \pi_{t}^{*}\right)+\xi_{p}^{*}\left(w_{t}^{*}+\psi_{t}^{*}\right) \varepsilon_{c p, t}^{*},
$$

where

\footnotetext{
${ }^{1}$ If I set $\phi_{q}=0$ I obtain the usual UIP condition.
} 


$$
\begin{gathered}
\xi_{p^{*}}^{*}=\frac{\left(1-\theta_{p}^{*}\right)\left(1-\beta \theta_{p}^{*}\right)}{\theta_{p}^{*}\left(1+\omega_{p} \varepsilon_{p}\right)}, \\
\psi_{t}^{*}=\left(1+\omega_{p}\right) \varepsilon_{a, t}^{*}-\omega_{p} y_{t}^{*} .
\end{gathered}
$$

Wage setting behavior of foreign households is described by the wage Phillips curve

$$
\pi_{t}^{w^{*}}-\delta_{w}^{*} \pi_{t-1}^{w^{*}}=\beta E_{t}\left(\pi_{t+1}^{w^{*}}-\delta_{w}^{*} \pi_{t}^{w^{*}}\right)+\xi_{w}^{*}\left(v_{t}^{*}-w_{t}^{*}\right),
$$

where

$$
\begin{gathered}
\xi_{w}^{*}=\frac{\left(1-\theta_{w}^{*}\right)\left(1-\beta \theta_{w}^{*}\right)}{\theta_{w}^{*}\left(1+\varphi^{*} \varepsilon_{w}\right)}, \\
v_{t}^{*}=\varphi^{*}\left(y_{t}^{*}-\varepsilon_{l, t}^{*}\right)+\frac{\sigma^{*}}{1-h^{*}}\left(y_{t}^{*}-h^{*} y_{t-1}^{*}\right) .
\end{gathered}
$$

Inflation, wage inflation and the real wage in the foreign economy are connected in an identity

$$
w_{t}^{*}=\pi_{t}^{w^{*}}-\pi_{t}^{*}+w_{t-1}^{*} .
$$

Foreign block of the model is completed with the monetary policy rule in the form of modified Taylor rule, for the evolution of foreign nominal interest rates

$$
i_{t}^{*}=\rho_{i}^{*} i_{t-1}^{*}+\left(1-\rho_{i}^{*}\right)\left[\psi_{\pi}^{*} \pi_{t}^{*}+\psi_{y}^{*} y_{t}^{*}\right]+\varepsilon_{M, t}^{*} .
$$

\section{Estimation}

\section{Data}

Quarterly data of CZ and EA 12 from $1^{\text {st }}$ quarter 1999 to $3^{\text {rd }}$ quarter of 2010 were downloaded from the database of Eurostat, http://ec.europa.eu/eurostat. Figure 1 displays demeaned data which enter the estimation.

- ${ }^{o b s} y_{t}=y_{t}-y_{t-1},{ }^{o b s} y_{t}^{*}=y_{t}^{*}-y_{t-1}^{*}$ : demeaned 100*log differences of real GDP per capita. As a measure of GDP "Gross Domestic Product at Market Prices, Millions of Euro, Chain-linked Volumes, Reference Year 2000 (at 2000 Exchange Rates), Seasonally Adjusted and Adjusted Data by Working Days" is used, and as a measure of population "Total Population" is used. 
- ${ }^{o b s} \pi_{t}=\pi_{t},{ }^{o b s} \pi_{t}^{*}=\pi_{t}^{*}$ : demeaned $100 * \log$ differences of price index, as underlying index "HICP (2005=100), All Items" is used. Seasonally Adjusted by Tramoseats, using Demetra software.

- ${ }^{o b s} \pi_{t}^{w}=\pi_{t}^{w},{ }^{o b s} \pi_{t}^{w^{*}}=\pi_{t}^{w^{*}}$ : demeaned $100 * \log$ differences of wage index. An underlying index for wage inflation is "Labour Cost Index (Nace Rev.2) (2008=100) Wages and Salaries, Business Economy, Seasonally Adjusted and Adjusted Data by Working Days". This index starts at 1.Q 2000 so the first four values are computed from "Labour Cost Index $(2000=100)$ - Wages and Salaries, Industry and Services (excluding Public Administration), Seasonally Adjusted and Adjusted Data by Working Days".

- ${ }^{o b s} i_{t}=i_{t},{ }^{o b s} i_{t}^{*}=i_{t}^{*}$ : demeaned data of nominal interest rate (quarterlized, i.e. divided by four), as the measure "Money Market Interest Rates, 3-Month Rates" is used.

- ${ }^{o b s} q_{t}=q_{t}-q_{t-1}$ : demeaned $100 * \log$ differences of real exchange rate, "Euro/ECU Exchange Rates - Quarterly Data, Average, National Currency (including 'euro fixed' series for euro area countries), Czech Koruna" is used as the measure of nominal exchange rate.

- ${ }^{\text {obs }} s_{t}=s_{t}-s_{t-1}$ : demeaned $100 * \log$ differences of terms of trade. Terms of trade are calculated as a ratio of the deflator for imports to exports, "Exports of Goods and Services, Seasonally Adjusted and Adjusted Data by Working Days, Price index, $2000=100$, Based on National Currency (including 'euro fixed' series for euro area countries)" is used as the measure of export prices, as a measure of import prices "Imports of Goods and Services, Seasonally Adjusted and Adjusted Data by Working Days, Price index, 2000=100, Based on National Currency (including 'euro fixed' series for euro area countries)" is used.

\section{Calibration and Priors}

The model is formed by equations (1) - (21) and contains 21 endogenous variables, $\left\{c_{t}\right.$, $\left.y_{t}, i_{t}, a_{t}, q_{t}, s_{t}, \pi_{t}, \pi_{H, t}, \pi_{F, t}, \psi_{F, t}, w_{t}, \pi_{t}^{w}, v_{t}, \psi_{t}\right\}$ in the domestic economy and $\left\{y_{t}^{*}, i_{t}^{*}, \pi_{t}^{*}, w_{t}^{*}, \psi_{t}^{*}, \pi_{t}^{w^{*}}, v_{t}^{*}\right\}$ in the foreign economy. The model also contains $8 \mathrm{AR} 1$ processes for exogenous shocks $\left\{\varepsilon_{a, t}, \varepsilon_{g, t}, \varepsilon_{l, t}, \varepsilon_{s, t}, \varepsilon_{c f, t}, \varepsilon_{a, t}^{*}\right.$, $\left.\varepsilon_{g, t}^{*}, \varepsilon_{l, t}^{*}\right\}$ and 4 shocks in the form of IID process $\left\{\varepsilon_{M, t}, \varepsilon_{M, t}^{*}, \varepsilon_{c p, t}, \varepsilon_{c p, t}^{*}\right\}$. There are 45 parameters in the model. Interpretation of the parameters is presented in the Table 3. Except six parameters $\left(\beta, \varepsilon_{p}, \varepsilon_{w}, \chi, \omega_{p}\right.$ and $\alpha$ ) which are difficult to identify, all parameters are estimated using Metropolis-Hastings algorithm (using Dynare toolbox for Matlab). Discount factor $\beta$ is calibrated to be 0.9975 , which implies an annual steady state real interest rate of $1 \%$. This value roughly corresponds to the long term mean of an annual real interest rate in both economies. Elasticities of substitution between various goods $\mathcal{E}_{p}$ and labor inputs $\varepsilon_{w}$ are both set equal to 8 , 
following results reported in Woodford (2003, ch. 3) and imply average price and wage mark-up of $14 \%$. Following Benigno (2009), the parameter $\chi$ governing the debt elastic interest rate premium is fixed at 0.01 . Parameter $\omega_{p}$ is calibrated to be 0.33 , following Justiano-Preston (2010b). Parameter of openness of the Czech economy $\alpha$ is calibrated to be 0.35 , according to the share of export to the production ${ }^{1}$.

Prior setting of estimated parameters as well as their estimated values in the unrestricted variant are presented in Table 4. Prior means for Calvo parameters of price and wage stickiness $\theta_{p}, \theta_{F}, \theta_{p^{*}}, \theta_{w}$ and $\theta_{w^{*}}$ are set to be 0.6 , which implies average price (wage) contract duration of 7.5 months. Because of no microeconomic evidence on price and wage indexation I set very loose priors for these parameters, prior means equal to 0.5 and prior std. deviations equal to 0.2 . Parameter $\phi_{q}$ in modified UIP condition is estimated with prior mean equal to 0.2 and prior std. deviation equal to 0.1 . Priors for parameters in Taylor rule are set consistently with Taylor (1999). Although prior means for elasticities of interest rate to output $\psi_{y}$ and $\psi_{y}^{*}$ are set to be a little bit higher $(0.2$ instead 0.125$)$ and thus take into account changes in the behavior of central banks in recent crisis. In my opinion, at this time central banks (ECB and CNB) pay more attention to development in output than they did before crisis. Inverse elasticities of intertemporal substitution $\sigma \sigma^{*}$ are estimated with relatively loose priors with prior means set to be 1.0, following Galí (2008), and prior std. deviations equal to 0.7. Inverse Frisch elasticities of labor supply $\varphi \varphi^{*}$ are estimated with prior means set to be 2.0 and std. deviations equal to 0.7 , which are values commonly found in the business cycle literature. Parameters of habit formation $h$ and $h^{*}$ are estimated with prior means set to be 0.7 and prior std. deviations equal to 0.1 , as in Smets and Wouters (2003). Backward-looking parameters in AR1 processes for exogenous shocks are estimated with very loose priors, prior means equal to 0.5 and std. deviations equal to 0.2 .

\section{Model Comparison}

Asymmetry of shocks and structural differences can be seen (in our context) as significant differences in values of some structural parameters. The question is when some difference can be regarded as significant. We adopt the approach presented in Kolasa (2009) which is based on a model comparison using Bayes factor. The idea which lies beneath this approach is as follows: structural parameters can be modeled as common for both economies, or as different for both economies. If there truly exists a significant difference in values of some parameters, than models which allow for difference in these parameters should fit the data better than models with common values of these parameters. I can compare unrestricted model with restricted model where selected parameters are modeled as common, and hence find out which model fits the data better. If I find that the unrestricted model fits the data better, I can say that

\footnotetext{
${ }^{1}$ http://www.czso.cz/csu/tz.nsf/i/statistika_upresnuje_predstavy_o_otevrenosti_ceske_ekonomiky 
there exist structural differences in those parameters. Next subsection describes the method adopted for the model comparison.

\section{Bayes Factor}

The model comparison is based on the Bayes factor (BF). The Bayes factor is a specific case of posterior odds (PO), when prior probabilities of competing models are set as equal. The Bayes factor of model $i$ and $j\left(B F_{i j}\right)$ is a Bayesian statistic calculated from (log) marginal likelihood ${ }^{1}$ (acquired from Bayesian estimation) as

$$
B F_{i j}=\frac{p\left(Y_{T} \mid M_{i}\right)}{p\left(Y_{T} \mid M_{j}\right)}=\exp \left(\log \left(p\left(Y_{T} \mid M_{i}\right)\right)-\log \left(p\left(Y_{T} \mid M_{j}\right)\right)\right)
$$

where $p\left(Y_{T} \mid M_{i}\right)$ is a marginal likelihood of model $i$ and $\log \left(p\left(Y_{T} \mid M_{i}\right)\right)$ is a $\log$ marginal likelihood of model $i{ }^{2}$ The Bayes factor shows us how much more probable model $i$ is than model $j$. DeJong and Dave (2007, p. 242) show an interpretation ${ }^{3}$ of $B F$ values

- 1-3 - "very slight evidence"

- 3-10 - "slight evidence"

- 10-100 - "strong to very strong evidence"

- 100 and higher - "decisive evidence"

This interpretation shows us how strong the evidence of the Bayes factor about that whether model $i$ explains the data better then model $j$ is. It is obvious that it holds $B F_{i / j}=1 / B F_{j / i}$.

\section{Sources of Structural Differences}

Table 1 displays calculated Bayes factors of unrestricted model versus restricted variants, where selected parameters are modeled as common.

We can see that there is almost no evidence in favor of heterogeneity in structural parameters related to household preferences. Although Bayes factor slightly favors the unrestricted variant before the variant with restriction on the inverse elasticity of labor supply $\varphi(\mathrm{BF}=1.29)$ and before the variant with restriction on the elasticity between domestic and foreign goods $\eta(\mathrm{BF}=1.15)$, these values of Bayes factor bring only very slight evidence in favor of heterogeneity in these parameters. Moreover, Bayes factor also favors the variant with restriction on all parameters related to household

\footnotetext{
${ }^{1}$ Calculation of log marginal likelihood is based on the Laplace approximation.

${ }^{2}$ It is more convenient to use log marginal likelihood because their numerical computation is much easier. In the following text I display my results using log marginal likelihood.

${ }^{3}$ Similar interpretation can be found in Jeffreys (1961) or Kass and Raftery (1995).
} 
REVIEW OF ECONOMIC PERSPECTIVES

preferences before unrestricted variant $(\mathrm{BF}=0.28)$. This value of Bayes factor brings slight evidence in favor of homogeneity in household preferences. 
Table 1: Bayes Factors and Log Marginal Likelihood - Structural Parameters

\begin{tabular}{|c|c|c|c|}
\hline $\mathrm{i}$ & restriction & $\mathrm{BF}_{0, \mathrm{i}}$ & $\log \left(\mathrm{p}\left(\mathrm{Y}_{\mathrm{T}} \mid \mathrm{M}_{\mathrm{i}}\right)\right)$ \\
\hline 0 . & unrestricted & 1 & -417.16 \\
\hline 1. & $\sigma=\sigma^{*}$ - inv. elasticity of intertemporal subs. & 0.61 & -416.67 \\
\hline 2. & $\varphi=\varphi^{*}$ - inv. elasticity of labor supply & 1.29 & -417.42 \\
\hline 3. & $h=h^{*}$ - habit formation in consumption & 0.49 & -416.44 \\
\hline 4. & $\eta=\eta^{*}-$ elasticity between dom. and for. goods & 1.15 & -417.30 \\
\hline 5. & household preferences (1-4) & 0.28 & -415.88 \\
\hline 6. & $\theta_{p}=\theta_{p}^{*}-$ price stickiness & 1.34 & -417.46 \\
\hline 7. & $\delta_{p}=\delta_{p}^{*}$ - price indexation & 5.41 & -418.85 \\
\hline 8. & $\theta_{w}=\theta_{w}^{*}-$ wage stickiness & 1.96 & -417.84 \\
\hline 9. & $\delta_{w}=\delta_{w}^{*}-$ wage indexation & 1.23 & -417.37 \\
\hline 10. & price formation - stickiness and indexation $(6,7)$ & 2.29 & -417.99 \\
\hline 11. & wage formation - stickiness and indexation $(8,9)$ & 2.56 & -418.10 \\
\hline 12. & price and wage formation $(10,11)$ & 6.06 & -418.96 \\
\hline 13. & $\rho_{i}=\rho_{i}^{*}-$ interest rate smoothing & $3.32 * 10^{3}$ & -425.27 \\
\hline 14. & $\psi_{\pi}=\psi_{\pi}^{*}$ - elasticity of interest rate to inflation & 2.28 & -417.99 \\
\hline 15. & $\psi_{y}=\psi_{y}^{*}$ - elasticity of interest rate to output & 0.70 & -416.80 \\
\hline 16. & monetary policy rule (13-15) & $2.31 * 10^{3}$ & -424.91 \\
\hline
\end{tabular}

Note: Own calculations

Nevertheless, we should be careful to interpret this result as an evidence of quite homogenous household preferences. Parameters related to household preferences are known to be weakly identifiable, and the result of homogeneity can be just a reflection of common priors. A look on credible intervals of these parameters, see Table 4, confirms this weak identifiability of parameters related to household preferences, especially in the case of inverse Frisch elasticities of labor supply $\varphi$ and $\varphi^{*}$. Therefore, results should be rather interpreted as I did not find substantial evidence in favor of heterogeneity in household preferences. 
I found out that there are some differences between the Czech economy and Euro Area in the price and wage formation $(\mathrm{BF}=6.06)$, the greatest one being the degree of price indexation $\delta_{p}$, as suggested by Bayes factor $(\mathrm{BF}=5.41)$ and by the difference in their estimated values in the unrestricted variant ( $\delta_{p}=0.17$ in $\mathrm{CZ}$ vs. $\delta_{p}^{*}=0.51$ in EA). It seems that Czech firms index their prices less than their foreign counterparts do. It also suggests that inflation dynamics in the Euro Area is more adaptive and backwardlooking while inflation dynamics in the Czech economy is more characterized by forward-looking nature of price setting. Although Bayes factor favors the unrestricted variant before all variants with some restriction on price and wage formation, these values provide only slight evidence in favor of heterogeneity in price and wage formation.

As regards monetary policy rules, I find substantial difference in the degree of interest rate smoothing. Bayes factor brings the decisive evidence for this conclusion $\left(\mathrm{BF}=3.32 * 10^{3}\right)$, although estimated values of this parameter in the unrestricted variant do not differ so much $\left(\rho_{i}=0.93\right.$ in CZ vs. $\rho_{i}^{*}=0.84$ in EA). It seems that the ECB does not smooth their interest rates as much as the CNB does.

\section{Asymmetry of Shocks}

Table 2 presents results for restrictions connected with structural shocks. Bayes factors bring strong evidence for difference in volatility of labor supply shocks $(\mathrm{BF}=39.62)$, and a very slight evidence for difference in volatility of preference shocks $(B F=2.95)$. These two differences also contribute to almost strong evidence in favor of overall heterogeneity in volatility of structural shocks $(\mathrm{BF}=9.97)$.

The results for persistence of structural shocks are rather mixed. Estimated values of these parameters in the unrestricted variant seem to be substantially different between both economies, see Table 4 . Nevertheless, Bayes factor favors variants with restriction on the persistence of structural shocks before the unrestricted variant, which should suggest that there are no differences in persistence of structural shocks. However, adding restriction on persistence of structural shocks to the variant which also has a restriction on volatility of structural shocks significantly worsens the empirical data fit of this variant and leads to decisive evidence $\left(\mathrm{BF}=2.88^{*} 10^{5}\right)$ in favor of the unrestricted variant. It seems that there are substantial differences in overall persistence and volatility of structural shocks, however, this result reveals itself only in testing this joint hypothesis.

Table 2: Bayes Factors and Log Marginal Likelihood - Structural Shocks

\begin{tabular}{|c|l|l|l|}
\hline $\mathrm{i}$ & Restriction & $\mathrm{BF}_{0, \mathrm{i}}$ & $\log \left(\mathrm{p}\left(\mathrm{Y}_{\mathrm{T}} \mid \mathrm{M}_{\mathrm{i}}\right)\right)$ \\
\hline 0. & Unrestricted & 1 & -417.16 \\
\hline 1. & $\sigma_{a}=\sigma_{a}^{*}-$ volatility of technology shocks & 0.83 & -416.98 \\
\hline 2. & $\sigma_{g}=\sigma_{g}^{*}$ - volatility of preference shocks & 2.95 & -418.25 \\
\hline
\end{tabular}




\begin{tabular}{|c|l|l|l|}
\hline 3. & $\sigma_{l}=\sigma_{l}^{*}-$ volatility of labor supply shocks & 39.62 & -420.84 \\
\hline 4. & $\sigma_{M}=\sigma_{M}^{*}-$ volatility of monetary shocks & 0.17 & -415.39 \\
\hline 5. & $\sigma_{c p}=\sigma_{c p}^{*}-$ volatility of cost-push shocks & 0.41 & -416.27 \\
\hline 6. & volatility of shocks (1-5) & 9.97 & -419.46 \\
\hline 7. & $\rho_{a}=\rho_{a}^{*}-$ persistence of technology shocks & 0.49 & -416.45 \\
\hline 8. & $\rho_{g}=\rho_{g}^{*}-$ persistence of preference shocks & 0.43 & -416.33 \\
\hline 9. & $\rho_{l}=\rho_{l}^{*}-$ persistence of labor supply shocks & 0.72 & -416.83 \\
\hline 10. & persistence of shocks (7-9) & 0.17 & -415.37 \\
\hline 11. & persistence and volatility of shocks (4,10) & $2.88^{*} 10^{5}$ & -429.73 \\
\hline 12. & no correlations of shocks & 168.29 & -422.29 \\
\hline 13. & almost perfect correlations of shocks & $7.76^{*} 10^{48}$ & -529.73 \\
\hline
\end{tabular}

Note: Own calculations

I also compare the unrestricted variant with the variant, where corresponding shocks in both economies are modelled as uncorrelated, and with the variant where corresponding shocks in both economies are modelled as almost perfectly correlated. ${ }^{1}$ Bayes factor favors the unrestricted variant before the variant with uncorrelated shocks $(B F=168.29)$, and also strongly favors the unrestricted variant before the variant with almost perfectly correlated shocks $\left(\mathrm{BF}=7.76^{*} 10^{48}\right)$. It seems that allowing for correlations between corresponding shocks in both economies (and estimating these correlations) improves the data fit of DSGE models significantly.

According to the estimations of correlations between corresponding shocks, see Table 4, we can say that the most correlated shocks are monetary shocks (cor=0.39) and preference shocks (cor $=0.38$ ). Correlations of these shocks are statistically significant on the significance level $\alpha=0.01$. Correlations of other shocks are not statistically significant even on the significance level $\alpha=0.1$. These results suggest that there exists a big asymmetry between shocks in the Czech economy and the Euro Area 12. However, we should be careful with this interpretation. Except for the monetary shocks and costpush shocks, the correlations are not between whole shocks (represented by AR1 processes) but only between innovations in these shocks. If I calculate correlations between smoothed AR1 processes representing these shocks, I get slightly different results. Correlations are now a little bit higher. Preference shocks are now highly correlated with correlation equal to 0.62 , correlations of technology shocks and labor

${ }^{1}$ Almost perfect correlation means correlation equal to 0.95 . It is impossible to estimate this model (using all previously mentioned time series) with correlation of structural shocks equal to 1. I decided to use this approximation, following Kolasa (2009). 
supply shocks are also higher, and for technology shocks it is equal to 0.34 and for labor supply shocks it is equal to 0.21 . However, these values are still rather low which suggest a big asymmetry between shocks in the Czech economy and the Euro Area 12.

\section{Impact of Structural Differences}

Structural differences can be also seen as differences in the behaviour of both economies. I can compare the behaviour of both economies in responses to various shocks, by using impulse-response functions. Figure 2 displays impulse-response functions of selected variables to various shocks. I restrict my analysis to the three most important macroeconomic variables: output, inflation and interest rate. Every subfigure displays a response of the domestic variable to the domestic shock and a response of the foreign variable to the foreign shock of the same type. ${ }^{1}$ I find it more meaningful to compare responses of domestic and foreign variables to shocks of the same type, where magnitude and persistence of these shocks is given by their estimated posterior means. Loosely speaking, I compare responses to shocks of the same type, with their average magnitude and persistence. This comparison covers structural differences as well as differences in persistence and volatility of structural shocks.

As regards preference shocks, it seems that there are no substantial differences in the behaviour of the main macroeconomic variables. Although magnitude of preference shocks is two times larger in the Czech economy than in the Euro Area 12, responses of examined variables show a very similar pattern. Nevertheless, the initial response of domestic output is larger than the initial response of foreign output, response of domestic inflation is a little bit larger and more persistent than response of foreign inflation, and response of domestic interest rate is a little bit more persistent than response of foreign interest rate.

On the other hand, responses of the main macroeconomic variables to technology shocks show substantial differences. Responses of domestic variables are much larger and display more gradual and hump-shaped pattern than responses of foreign variables. It is influenced by much larger volatility and persistence of domestic technology shocks.

Responses of the main macroeconomic variables to labor supply shocks are also different between both economies. Responses of foreign variables are much more gradual and sluggish than responses of domestic variables.

As regards monetary shocks, the response of the domestic output is larger than the response of the foreign output but the adjustment of the domestic output is more rapid. There is almost no response of the foreign inflation to foreign monetary shock while the response of domestic inflation to domestic monetary shock displays substantial decline followed by gradual recovery.

Volatility of cost-push shocks in the domestic economy is much larger than in the foreign economy. This contributes to the fact that responses of foreign variables to costpush shocks are larger and more volatile than responses of domestic variables.

\footnotetext{
${ }^{1}$ I consider the Czech economy as the domestic economy and Euro Area 12 as the foreign economy.
} 


\section{Conclusion}

I investigated asymmetric shocks and structural differences between the Czech economy and the Euro Area 12. At first, I examined asymmetry of shocks and sources of structural differences, using model comparison based on the Bayes factor. I did not find any substantial evidence in favor of heterogeneity in household preferences. I did find though some slight differences in price and wage formation and a substantial difference in interest rate smoothing. However, the main differences are in timing, persistence and volatility of structural shocks.

Apart from that, I also examined impact of structural differences and differences in persistence and volatility of structural shocks on the behavior of both economies, using analysis of impulse-response functions. As regards preference shocks, I found no substantial differences in the behaviour of the main macroeconomic variables. On the other hand, I did find much larger volatility and persistence of domestic technology shocks. This contributes to the fact that responses of domestic variables to technology shocks are much larger and display more gradual and hump-shaped pattern than responses of foreign variables. I also found out that responses of foreign variables to labour supply shocks are much more gradual and sluggish than responses of domestic variables. As regards monetary shocks, I discovered that there is almost no response of foreign inflation to foreign monetary shock while response of domestic inflation to domestic monetary shocks displays substantial decline followed by gradual recovery. Responses of foreign variables to cost-push shocks are larger and more volatile than responses of domestic variables.

\section{References}

ADOLFSON, M., LASÉEN, S., LINDÉ, J., VILLANI, M. (2008). Evaluating An Estimated New Keynesian Small Open Economy Model. Journal of Economic Dynamics and Control. 32(8), pp. 2690-2721.

ALEXIUS, A., POST, E. (2008). Exchange Rates and Asymmetric Shocks in Small Open Economies. Empirical Economics. 35(3), pp. 527-541. DOI: 10.1007/s00181-0070177-7

AMISANO, G., GIAMMARIOLI, N., STRACCA, L. (2009). EMU and the Adjustment to Asymmetric Shocks: the Case of Italy. ECB Working Paper No. 1128.

ANGELONI, I., EHRMANN, M. (2004). Euro Area Inflation Differentials. ECB Working Paper No. 388.

BAYOUMI, T., EICHENGREEN, B. (1992). Shocking Aspects of European Monetary Unification. NBER Working Paper No. 3949.

BENIGNO, P. (2009). Price Stability with Imperfect Financial Integration. Journal of Money, Credit and Banking. 41(1), pp. 121-149. DOI: 10.1111/j.15384616.2008.00201.x

BENIGNO, P., LOPÉZ-SALIDO, J. D. (2006). Inflation Persistence and Optimal Monetary Policy in the Euro Area. Journal of Money, Credit and Banking. 38(3), pp. 587-614. 
CALVO, G. (1983). Staggered Prices in a Utility Maximizing Framework. Journal of Monetary Economics. 12(3), pp. 383-398.

CAMPA, J. M., GONZALEZ MINGUEZ, J. M. (2006). Differences in Exchange Rate Pass-through in the Euro Area. European Economic Review. 50(1), pp. 121-145. DOI:10.1016/j.euroecorev.2004.12.002

CECCHETTI, S. G. (1999). Legal Structure, Financial Structure, and the Monetary Policy Transmission Mechanism. Economic Policy Review. 5(2), pp. 9-28.

DEJONG, D. N., DAVE, C. (2007). Structural Macroeconometrics. New Jersey: Princeton University Press.

DEMERTZIS, M., HUGUES HALLETT, A. (1998). Asymmetric Transmission Mechanisms and the Rise in European Unemployment: A Case of Structural Differences or of Policy Failure? Journal of Economic Dynamics and Control. 22(6), pp. 869-886.

DRIVER, R. L., WREN-LEWIS, S. (1999). European Monetary Union and Asymmetric Shocks in a New Keynesian Model. Oxford Economic Papers. 51(4), 665-688.

ERCEG, C. J., HENDERSON, D. W., LEVIN, A. T. (2000). Optimal Monetary Policy with Staggered Wage and Price Contracts. Journal of Monetary Economics. 46(2), pp. 281-313. DOI:10.1016/S0304-3932(00)00028-3

FABIANI, F., MORGAN, J. (2003). Aggregation and Euro Area Phillips Curves. ECB Working Paper No. 213.

GALÍ, J. (2008). Monetary Policy, Inflation, and the Business Cycle: An Introduction to the New Keynesian Framework. New Jersey: Princeton University Press.

GALÍ, J., MONACELLI, T. (2005). Monetary Policy and Exchange Rate Volatility in a Small Open Economy. Review of Economic Studies. 72(3), pp. 707-734.

JEFFREYS, H. (1961). Theory of Probability. (3rd ed.) Oxford: Oxford University Press.

JONDEAU, E., SAHUC, J. G. (2007). Testing Heterogeneity within the Euro Area. Banque de France, Documents de Travail 181.

JONDEAU, E., SAHUC, J. G. (2008). Testing Heterogeneity within the Euro Area. Economics Letters. 99(1), pp. 192-196.

JUSTINIANO, A., PRESTON, B. (2010a). Monetary Policy and Uncertainty in an Empirical Small Open Economy Model. Journal of Applied Econometrics. 25(1), pp. 93-128. DOI: 10.1002/jae.1153

JUSTINIANO, A., PRESTON, B. (2010b). Can Structural Small Open Economy Models Account for the Influence of Foreign Disturbances? Journal of International Economics. 81(1), pp. 61-74. DOI: 10.1016/j.jinteco.2010.01.001

JUSTINIANO, A., PRESTON, B. (2006). Can Structural Small Open Economy Models Account for the Influence of Foreign Disturbances? CAMA Working Paper 12/2006. 
KASS R. E., RAFTERY A. E. (1995). Bayes Factors. Journal of the American Statistical Association. 90(430), pp. 773-795.

KOLASA, M. (2009). Structural heterogeneity or asymmetric shocks? Poland and the euro area through the lens of a two-country DSGE model. Economic Modelling. 26(6), pp. 1245-1269.

MONACELLI, T. (2003). Monetary Policy in a Low Pass-through Environment. ECB Working Paper No. 227.

PAUER, F. (1996). Will Asymmetric Shocks Pose a Serious Problem in EMU? Oesterreichische Nationalbank, Working Paper 23.

PYTLARCZYK, E. (2005). An Estimated DSGE Model for the German Economy within the Euro Area. Discussion Paper Series 1: Economic Studies 2005, 33, Deutsche Bundesbank.

SMETS, F., WOUTERS, R. (2003). An Estimated Dynamic Stochastic General Equilibrium Model of the Euro Area. Journal of the European Economic Association. 1(5), pp. 1123-1175.

TAYLOR, J. B. (1999). A Historical Analysis of Monetary Policy Rules. In Taylor (ed), Monetary Policy Rules, Chicago: University of Chicago Press.

VERHOEF, B. A. (2003). The (A)Symmetry of Shocks in the EMU. Netherlands Central Bank, DNB Staff Reports 106.

WOODFORD, M. (2003). Interest and Prices: Foundations of a Theory of Monetary Policy. New Jersey: Princeton University Press. 


\section{Tables and Figures}

Table 3: Interpretation of Parameters

\begin{tabular}{|c|c|c|}
\hline parameter & Interpretation & restriction \\
\hline$\beta$ & discount factor & $\langle 0,1\rangle$ \\
\hline$\alpha$ & openness of the economy & $\langle 0,1\rangle$ \\
\hline $\mathcal{E}_{p}$ & elasticity of substitution among goods & $\langle 1, \infty)$ \\
\hline$\varepsilon_{w}$ & elasticity of substitution among labor types & $\langle 1, \infty)$ \\
\hline$\omega_{p}$ & $-f^{\prime \prime} \bar{Y} /\left(f^{\prime}\right)^{2}$ & $\langle 0, \infty)$ \\
\hline$\chi$ & elasticity of interest rate to debt & $\langle 0, \infty)$ \\
\hline$\sigma, \sigma^{*}$ & inv. elast. of intertemporal substitution & $\langle 0, \infty)$ \\
\hline$\varphi, \varphi^{*}$ & inv. elast. of labor supply & $\langle 0, \infty)$ \\
\hline$h, h^{*}$ & habit formation & $\langle 0,1\rangle$ \\
\hline$\eta, \eta^{*}$ & elast. of subst. among H/F goods & $\langle 0, \infty)$ \\
\hline$\theta_{p}, \theta_{p}^{*}$ & Calvo parameter for producers & $\langle 0,1\rangle$ \\
\hline$\theta_{F}$ & Calvo parameter for importers & $\langle 0,1\rangle$ \\
\hline$\theta_{w}, \theta_{w}^{*}$ & Calvo parameter for households & $\langle 0,1\rangle$ \\
\hline$\delta_{p}, \delta_{p}^{*}$ & indexation of producers & $\langle 0,1\rangle$ \\
\hline$\delta_{F}$ & indexation of importers & $\langle 0,1\rangle$ \\
\hline$\delta_{w}, \delta_{w}^{*}$ & indexation of households & $\langle 0,1\rangle$ \\
\hline$\psi_{\pi}, \psi_{\pi}^{*}$ & elasticity of interest rate to inflation & $\langle 0, \infty)$ \\
\hline$\psi_{y}, \psi_{y}^{*}$ & elasticity of interest rate to output & $\langle 0, \infty)$ \\
\hline$\rho_{i}, \rho_{i}^{*}$ & interest rate smoothing & $\langle 0,1\rangle$ \\
\hline$\rho_{a}, \rho_{a^{*}}$ & AR1 parameters for technology shocks & $\langle 0,1\rangle$ \\
\hline
\end{tabular}




\begin{tabular}{|c|c|c|}
\hline$\rho_{g}, \rho_{g *}$ & AR1 parameters for preference shocks & $\langle 0,1\rangle$ \\
\hline$\rho_{l}, \rho_{l^{*}}$ & AR1 parameters for labor supply shocks & $\langle 0,1\rangle$ \\
\hline$\rho_{c f}$ & AR1 parameter for importer's cost push shock & $\langle 0,1\rangle$ \\
\hline$\rho_{s}$ & AR1 parameter for risk premium shock & $\langle 0,1\rangle$ \\
\hline$\sigma_{a}, \sigma_{a^{*}}$ & std. dev. of technology shocks & $\langle 0, \infty)$ \\
\hline$\sigma_{g}, \sigma_{g^{*}}$ & std. dev. of preference shocks & $\langle 0, \infty)$ \\
\hline$\sigma_{l}, \sigma_{l^{*}}$ & std. dev. of labor supply shocks & $\langle 0, \infty)$ \\
\hline$\sigma_{c p}, \sigma_{c p^{*}}$ & std. dev. of producer's cost-push shocks & $\langle 0, \infty)$ \\
\hline$\sigma_{M}, \sigma_{M^{*}}$ & std. dev. of monetary shocks & $\langle 0, \infty)$ \\
\hline$\sigma_{c f}$ & std. dev. of importer's cost push shock & $\langle 0, \infty)$ \\
\hline$\sigma_{s}$ & std. dev. of risk premium shock & $\langle 0, \infty)$ \\
\hline$c o r_{a}$ & correlation of technology shocks $\mathcal{E}_{a, t}, \mathcal{E}_{a, t}^{*}$ & $\langle-1,1\rangle$ \\
\hline $\operatorname{cor}_{g}$ & correlation of preference shocks $\varepsilon_{g, t}, \varepsilon_{g, t}^{*}$ & $\langle-1,1\rangle$ \\
\hline $\operatorname{cor}_{l}$ & correlation of labor supply shocks $\varepsilon_{l, t}, \mathcal{E}_{l, t}^{*}$ & $\langle-1,1\rangle$ \\
\hline $\operatorname{cor}_{c p}$ & correlation of cost-push shocks $\varepsilon_{c h, t}, \varepsilon_{c p, t}^{*}$ & $\langle-1,1\rangle$ \\
\hline $\operatorname{cor}_{m}$ & correlation of monetary shocks $\varepsilon_{l, M}, \varepsilon_{M, t}^{*}$ & $\langle-1,1\rangle$ \\
\hline
\end{tabular}


Table 4: Estimated Parameters - unrestricted variant

\begin{tabular}{|c|c|c|c|c|c|c|c|}
\hline par. & $\begin{array}{l}\text { prior } \\
\text { mean }\end{array}$ & $\begin{array}{l}\text { prior } \\
\text { std. } \\
\text { dev. }\end{array}$ & $\begin{array}{l}\text { prior } \\
\text { dist. }\end{array}$ & $\begin{array}{l}\text { post. } \\
\text { mean } \\
\text { CZ }\end{array}$ & $\begin{array}{l}90 \% \text { cred. } \\
\text { interval } \\
\mathrm{CZ}\end{array}$ & $\begin{array}{l}\text { post. } \\
\text { mean } \\
\text { EA }\end{array}$ & $\begin{array}{l}90 \% \text { cred. } \\
\text { interval } \\
\text { EA }\end{array}$ \\
\hline$\sigma, \sigma^{*}$ & 1.0 & 0.7 & $\mathrm{G}$ & 0.79 & 0.251 .29 & 0.78 & 0.231 .30 \\
\hline$\varphi, \varphi^{*}$ & 2.0 & 0.7 & $\mathrm{G}$ & 1.75 & 0.802 .66 & 2.40 & 1.193 .56 \\
\hline$h, h^{*}$ & 0.7 & 0.1 & B & 0.81 & 0.690 .93 & 0.79 & 0.690 .89 \\
\hline$\eta, \eta^{*}$ & 0.5 & 0.15 & $\mathrm{G}$ & 0.47 & 0.290 .65 & 0.42 & 0.300 .53 \\
\hline$\theta_{p}, \theta_{p}^{*}$ & 0.6 & 0.05 & B & 0.63 & 0.560 .70 & 0.67 & 0.600 .74 \\
\hline$\theta_{F}$ & 0.6 & 0.05 & B & 0.67 & 0.610 .73 & & \\
\hline$\theta_{w}, \theta_{w}^{*}$ & 0.6 & 0.05 & B & 0.57 & 0.520 .63 & 0.67 & 0.610 .73 \\
\hline$\delta_{p}, \delta_{p}^{*}$ & 0.5 & 0.2 & $\mathrm{~B}$ & 0.17 & 0.020 .31 & 0.51 & 0.220 .82 \\
\hline$\delta_{F}$ & 0.5 & 0.2 & B & 0.54 & 0.260 .82 & & \\
\hline$\delta_{w}, \delta_{w}^{*}$ & 0.5 & 0.2 & B & 0.54 & 0.240 .84 & 0.34 & 0.130 .53 \\
\hline$\psi_{\pi}, \psi_{\pi}^{*}$ & 1.5 & 0.15 & $\mathrm{G}$ & 1.62 & 1.401 .84 & 1.38 & 1.151 .60 \\
\hline$\psi_{y}, \psi_{y}^{*}$ & 0.5 & 0.15 & $\mathrm{G}$ & 0.19 & 0.110 .26 & 0.16 & 0.090 .23 \\
\hline$\rho_{i}, \rho_{i}^{*}$ & 0.8 & 0.05 & B & 0.93 & 0.920 .95 & 0.84 & 0.800 .87 \\
\hline$\rho_{a}, \rho_{a^{*}}$ & 0.5 & 0.2 & B & 0.93 & 0.870 .99 & 0.54 & 0.220 .86 \\
\hline$\rho_{g}, \rho_{g *}$ & 0.5 & 0.2 & B & 0.58 & 0.340 .82 & 0.70 & 0.570 .82 \\
\hline$\rho_{l}, \rho_{l^{*}}$ & 0.5 & 0.2 & B & 0.23 & 0.070 .39 & 0.36 & 0.170 .54 \\
\hline$\rho_{c f}$ & 0.5 & 0.2 & B & 0.88 & 0.820 .94 & & \\
\hline$\rho_{s}$ & 0.5 & 0.2 & B & 0.93 & 0.880 .98 & & \\
\hline$\sigma_{a}, \sigma_{a^{*}}$ & $\begin{array}{l}3.0 \\
0.5\end{array}$ & $\infty$ & I & 3.71 & 2.374 .98 & 1.03 & 0.112 .58 \\
\hline
\end{tabular}


Volume 11, Issue 3, 2011

\begin{tabular}{|l|l|l|l|l|l|l|l|}
\hline$\sigma_{g}, \sigma_{g^{*}}$ & $\begin{array}{l}6.0 \\
2.0\end{array}$ & $\infty$ & $\mathrm{I}$ & 7.91 & 3.6212 .63 & 2.82 & 1.554 .10 \\
\hline$\sigma_{l}, \sigma_{l^{*}}$ & $\begin{array}{l}25.0 \\
12.0\end{array}$ & $\infty$ & $\mathrm{I}$ & 37.66 & 27.7250 .0 & 11.19 & 5.3317 .02 \\
\hline$\sigma_{c p}, \sigma_{c p^{*}}$ & $\begin{array}{l}0.05 \\
0.3\end{array}$ & $\infty$ & $\mathrm{I}$ & 0.14 & 0.010 .47 & 0.36 & 0.210 .49 \\
\hline$\sigma_{M}, \sigma_{M^{*}}$ & 0.1 & $\infty$ & $\mathrm{I}$ & 0.10 & 0.080 .11 & 0.10 & 0.080 .11 \\
\hline$\sigma_{c f}$ & 0.3 & $\infty$ & $\mathrm{I}$ & 0.97 & 0.641 .28 & & \\
\hline$\sigma_{s}$ & 0.5 & $\infty$ & $\mathrm{I}$ & 0.16 & 0.070 .26 & & \\
\hline $\operatorname{cor}_{a}$ & 0 & 0.4 & $\mathrm{~N}$ & 0.21 & -0.310 .75 & & \\
\hline $\operatorname{cor}_{g}$ & 0 & 0.4 & $\mathrm{~N}$ & $0.38^{* * *}$ & 0.180 .59 & & \\
\hline $\operatorname{cor}_{l}$ & 0 & 0.4 & $\mathrm{~N}$ & 0.11 & -0.110 .33 & & \\
\hline $\operatorname{cor}_{c p}$ & 0 & 0.4 & $\mathrm{~N}$ & 0.19 & -0.410 .77 & & \\
\hline cor $_{m}$ & 0 & 0.4 & $\mathrm{~N}$ & $0.39^{* * *}$ & 0.190 .58 & & \\
\hline
\end{tabular}

Note: $G$ - gamma, $B$ - beta, I - inverse gamma, $N$ - normal 


\section{Figure 1: Data}
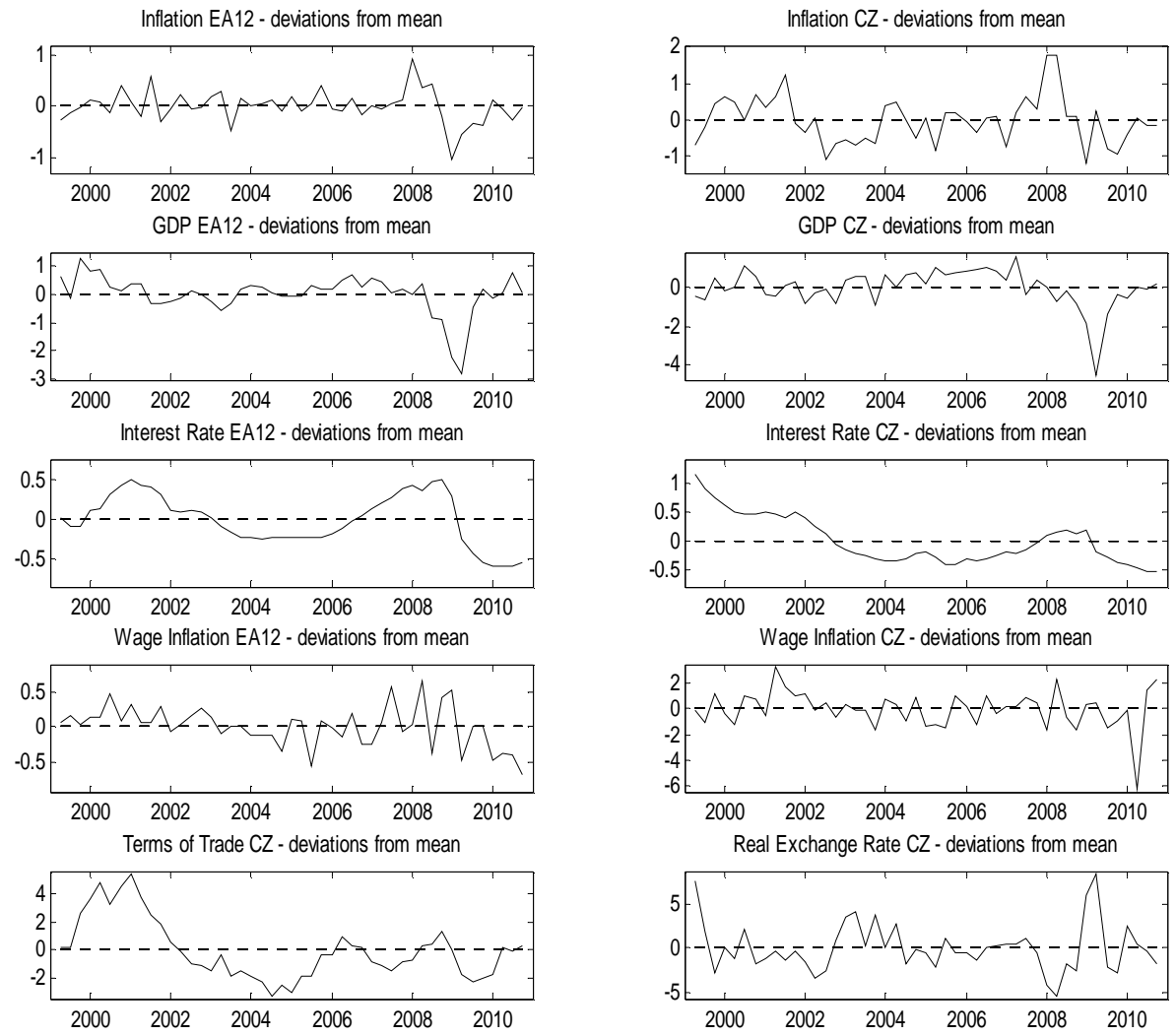
Figure 2: Impulse-Response Functions

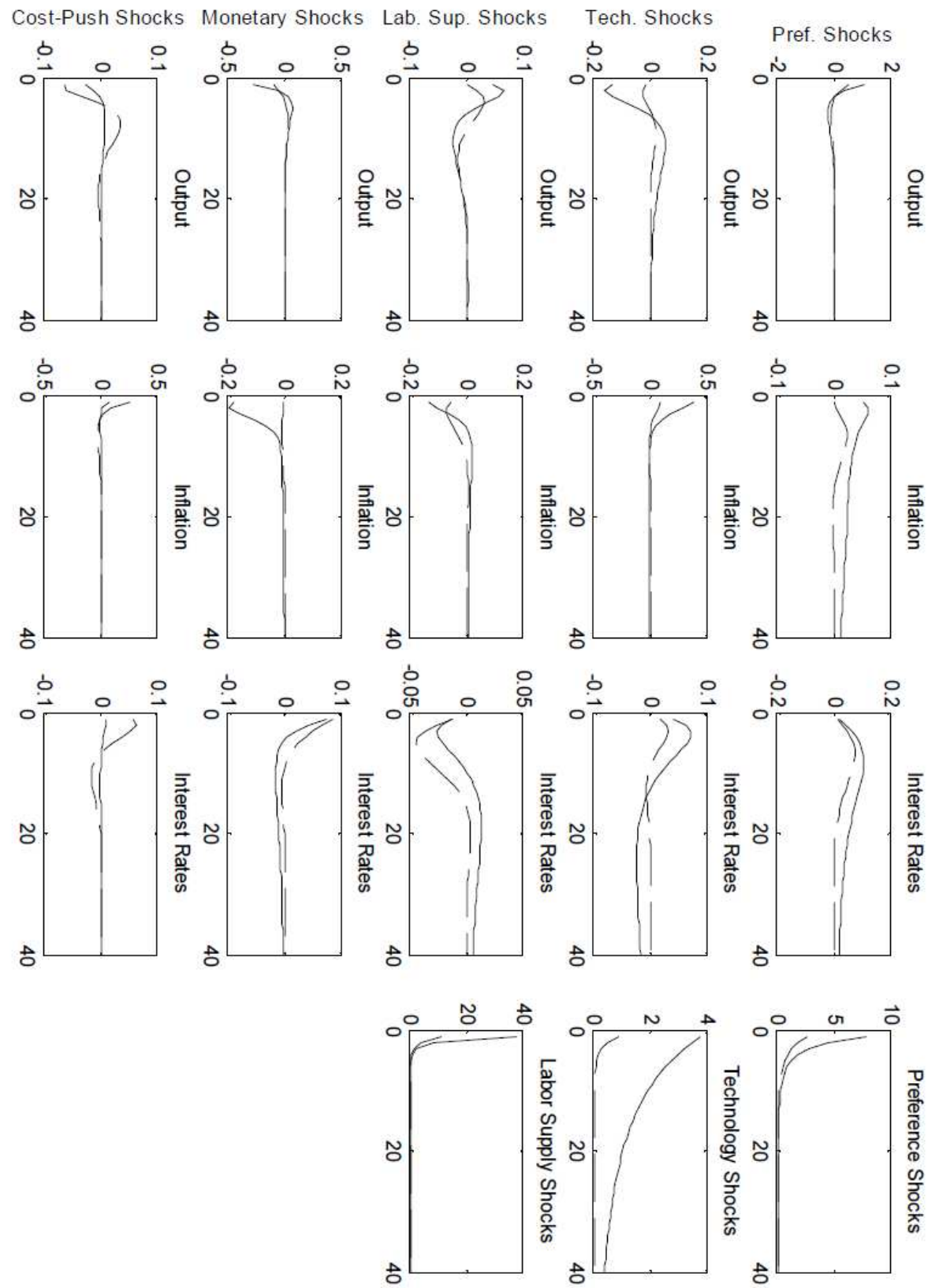

Note: solid line - responses of domestic variables to domestic shocks, dashed line responses of foreign variables to foreign shocks 